\title{
PARTICLE-SIZE DISTRIBUTION OF PULVERIZED SNOW
}

\author{
By H. H. G. Jellinek and Warren A. Schlueter \\ (U.S. Army Snow, Ice and Permafrost Research Establishment, Corps of Engineers, \\ Wilmette, Illinois)
}

\begin{abstract}
A microscopic method for the determination of particle-size distribution of pulverized snow was worked out. The method gives satisfactory distribution curves, presenting the number of particles as a function of their cross-sectional "areas". The measurements were made by means of a filar micrometer eyepiece, the snow particles being placed on a ruled glass slide, which was submerged in silicone oil to prevent evaporation. The time for the determination of a distribution can be appreciably shortened by estimating the size of the particles instead of measuring them, though the accuracy is not so high in this case.

RÉsumé. Une méthode employant le microscope a été mise au point pour l'étude de la distribution des granulométries dans la neige pulvérisée. Cette méthode donne des courbes de distribution satisfaisantes, présentant le nombre de grains en fonction de leurs "superficies" en section transversale. Les mesures ont été faites avec un oculaire-micromètre à fil, les grains de neige étant placés sur une règle en verre immergée dans une huile de silicone afin d'empêcher toute évaporation. Il est possible de réduire considérablement le temps nécessaire pour mesurer cette distribution en estimant la grosseur des grains au lieu de la mesurer, mais dans ce cas la méthode n'est pas aussi précise.
\end{abstract}

Zusammenfassung. Es wurde eine mikroskopische Methode zur Bestimmung der Teilchengrösse Verteilungen von gepulvertem Schnee ausgearbeitet. Die Methode gibt zufriedenstellende Verteilungskurven, in denen die Anzahl der Teilchen eine Funktion ihrer Querschnitte ist. Die Messungen wurden mit Hilfe eines Okularfadenmikrometers gemacht, wobei die Schneeteilchen auf eine mit einer Skala versehene Glaslamelle gebracht werden, das in Silikonöl eingetaucht war, um Verdampfung zu verhindern. Die Zeit zur Bestimmung einer Verteilung kann beträchtlich dadurch abgekürzt werden, dass man die Grösse der Teilchen schätzt anstatt sie zu messen, obwohl dann die Genauigkeit nicht so gut ist.

\section{INTRODUCTION}

Size distribution data on snow are of importance in connexion with its mechanical properties. A correlation between the mechanical properties and particle size is to be expected. For instance, the larger the surface area of a sample for a given weight, the larger the number of bridges which will be formed across the particles on compacting. The work described in this report was undertaken with the purpose of characterizing pulverized snow particles by determining their size distributions with respect to the cross-sectional areas of the snow particles. Distribution curves were obtained which make it possible to correlate in a practical way the particle-size distribution of snow with its mechanical properties. The first method attempted for obtaining a distribution involved the rate of sedimentation of the particles suspended in a suitable liquid. However, the snow particles agglomerated in the liquid and representative distributions could not be obtained. Several liquids such as kerosene, trimethylpentane and silicone oils of different kinematic viscosities (o. 65 cs., I $\cdot$ oo cs., Io cs.) were tried but without success. The addition of detergents did not improve the situation. Therefore, this sedimentation method had to be abandoned and a microscopic method was developed.

\section{Experimental Details}

\section{Snow samples}

Snow was ground in a mortar at $-20^{\circ} \mathrm{C}$. The pulverized snow was passed through two wire meshes of $150 \mu$ and $300 \mu$ size. Two snow fractions were obtained in this way; one fraction with particle-size ranging from 0 to $150 \mu$ and a second one ranging from 150 to $300 \mu$. These fractions were stored in glass containers with ground glass stoppers at $-20^{\circ} \mathrm{C}$.

\section{Procedure}

The snow to be measured was obtained by random sampling at $-20^{\circ} \mathrm{C}$. The snow was screened through a mesh just large enough to pass the largest particles of the sample. The 
particles were screened directly onto a microscope slide, which had a grid of squares of I $\mathrm{mm} .{ }^{2}$ each etched on it. An attempt to measure the particles by placing the slide directly under the microscope was abandoned, because serious sublimation occurred before the measurement of the particles could be completed. Reduction of the heat from the light source and placing the slide in a box saturated with water vapor did not reduce the rate of sublimation sufficiently.

Finally the following arrangement proved satisfactory, at a room temperature of $-5^{\circ} \mathrm{C}$. A microscope with a filar micrometer eyepiece was used. The slide containing the snow particles was submerged in silicone oil. The dish containing the slide rested on a table which could be moved in two dimensions in the horizontal plane. The light source was a fluorescent lamp. The light passed through a frosted glass plate and through a cell containing a 50 per cent water-methanol mixture. The liquid was tinted light green in order to ease eyestrain and to increase the contrast between the silicone oil and the snow particles. The vessel containing the silicone oil and the slide was elevated from the cell to allow circulation of cold air. Each time the slide was submerged, the arrangement was calibrated by means of the filar micrometer and the grid etched on the sample slide.

It was noted that, after about 2 to $4 \mathrm{hr}$. in the oil, the snow particles took on a rounded appearance; all sharp edges disappeared. Therefore, only about roo particles were placed on the slide at a time, so that measurements could be completed before the particles changed shape appreciably.

It was also noted that after 2 or 3 days the particles had completely disappeared. The water molecules probably diffuse through the silicone oil and evaporate. It is not unlikely that a change in particle size takes place when the snow is stored at $-20^{\circ} \mathrm{C}$. Over a period of a week or so, many fine particles formed on the sides and the tops of the glass containers. Thus it is not to be expected that the same size distribution would be found for a freshly ground sample and for one which had been kept for some time in a container.

In the procedure adopted finally, the snow sample was passed through a wire mesh before measuring in order to separate the particles which adhered to each other. It was generally possible to recognize the boundaries of the few individual particles which still clung together after sieving.

The maximum and minimum "diameters" of each particle were measured and the product of these values was taken as an indication of the size of the particle (this measurement is subsequently referred to as "area"). The measurements were expressed in terms of the filar micrometer divisions. These in turn were calibrated at the beginning and end of a series of readings by means of the grid on the glass slide. The average of the two calibrations was used for converting the drum divisions into centimeters.

The number-size distribution curves with respect to the "area" of the particles were obtained as follows. First, the particles were assigned to "area" intervals of suitable size. Secondly, the percentage of particles in each area interval was computed. Thirdly, the cumulative percentage values

$$
\int_{0}^{A} d \mathcal{N}=f(A)
$$

were plotted against the "area" values $(d \mathcal{N}$ is the percentage number of particles in an area interval $d A$ ). Fourthly, the derivative curve was obtained by graphically differentiating the cumulative curve with respect to the area. $d \mathcal{N} / d A$ was plotted against "area" $A$. The curve obtained is the number-size distribution curve with respect to the area. The area under the curve represents IOO particles since

$$
\int_{0}^{\infty}\left(\frac{d \mathcal{N}}{d A}\right) d A=\text { гоо. }
$$


The number average value of the area was obtained from

$$
\bar{A}=\frac{\Sigma A_{i} \mathcal{N}_{i}}{\mathcal{N}}
$$

and the standard deviation from

$$
\sigma=\sqrt{\frac{\sum_{0}^{\infty}\left(A_{i}-\bar{A}\right)^{2} \mathcal{N}_{i}}{\mathcal{N}-\mathrm{I}}},
$$

where $\bar{A}$ is the number average "area", $A_{i}$ is the mean "area" of the $i$ th interval and $\mathcal{N}_{i}$ is the number of particles in the $i$ th interval.

In order to reduce the time needed to measure and note a set of 200 to 300 particles, a tape recorder was used. The two micrometer-drum readings whose difference gave the dimension of every particle were recorded. When the desired number of particles had been measured, the entire set of readings was transcribed to paper. In some cases, the distributions were constructed from estimated particle-size values. In such instances, the two estimated dimensions were also recorded on tape. During the play-back, the dimensions of each particle were multiplied and the area itself transcribed to paper.

The time required to measure and transcribe the data for 300 particles is approximately $4 \frac{1}{2} \mathrm{hr}$. To estimate the same number and obtain the area of each particle takes approximately $\mathrm{I} \frac{1}{2} \mathrm{hr}$.

Given the areas of 300 particles, it requires an additional hour to draw the cumulative and derivative curves. The time for drawing the curves could be appreciably reduced by just drawing histograms, sacrificing some accuracy.

\section{EXPERIMENTAL Results}

\section{Fraction $150-300 \mu$}

Fig. I shows the percentage cumulative curve of the pulverized snow sample with a range of particle sizes from 150 to $300 \mu$. The curves for 100,200 , and 300 particles are shown. The area in this figure is given in drum division units. It is seen that at least 200 particles have to

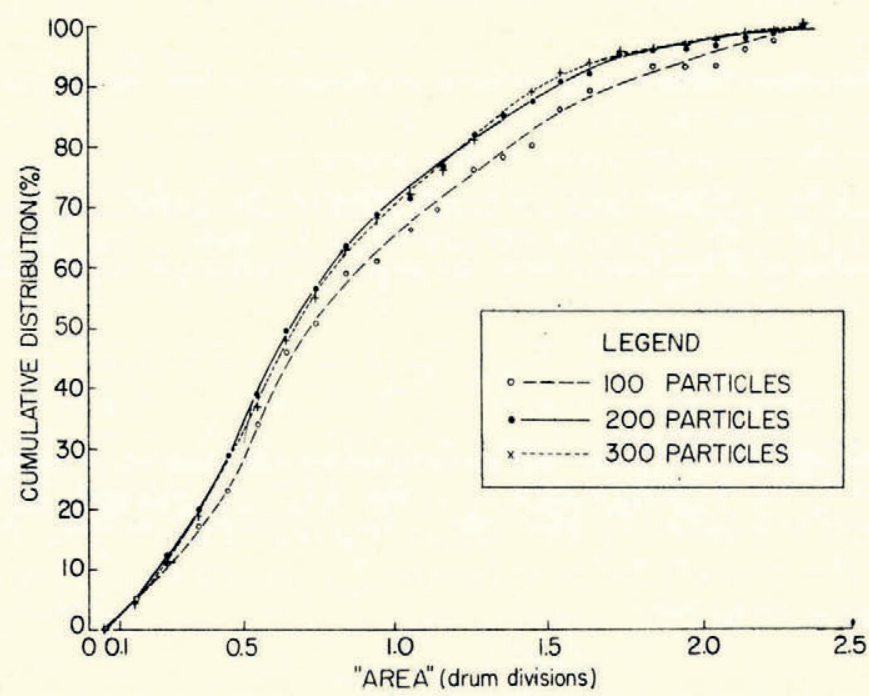

Fig. I. Cumulative particle-size distribution curve for 100,200 , and 300 snow particles, fraction $150-300 \mu$ 


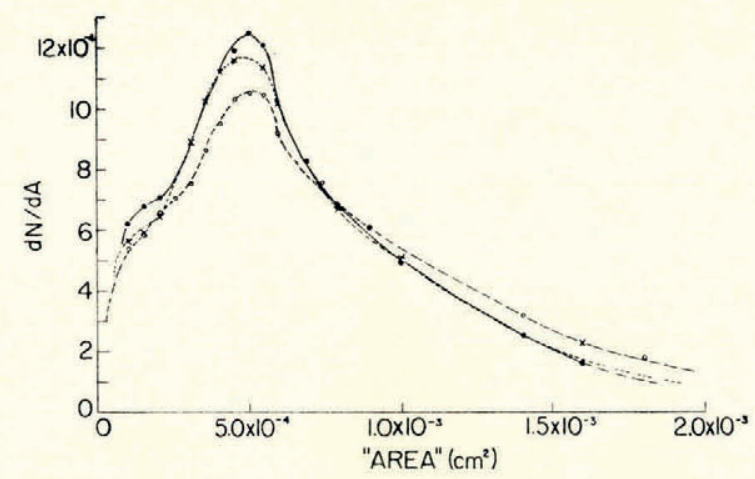

Fig. 2. Derivative particle-size distribution curve for 100,200 , and 300 snow particles, fraction $150-300 \mu$

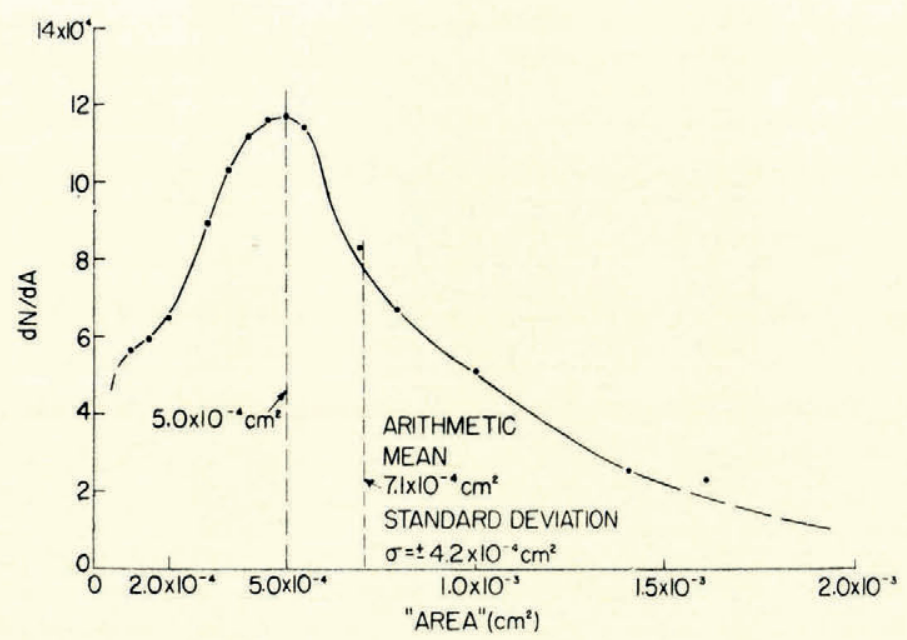

Fig. 3. Derivative particle-size distribution curve for 300 snow particles, fraction $150-300 \mu$

be measured before a representative curve is obtained. However, only ioo particles are needed to determine the most probable value, as can be seen from the derivative curves in Fig. 2; if only an approximate distribution is wanted, the measurement of roo particles seems to be sufficient in this range of particle sizes. Fig. 3 shows an enlarged drawing of the number distribution with respect to area for 300 particles.

Distributions were also obtained for this fraction by estimating the dimensions of the particles lying on the grid of the slide. Figs. 4 and 5 give the cumulative and derivative curves for two experiments where 200 particles each were estimated; for comparison the curve obtained by measurement is also shown. The estimated values are consistently smaller than the measured ones. This is due to a personal error in estimating. However, if the accuracy desired is not too great, the estimating of particles gives satisfactory curves and the time for obtaining them is appreciably shortened. Table I shows the most probable values, mean values, and standard deviations derived from the results obtained for the 150 to $300 \mu$ fraction. 


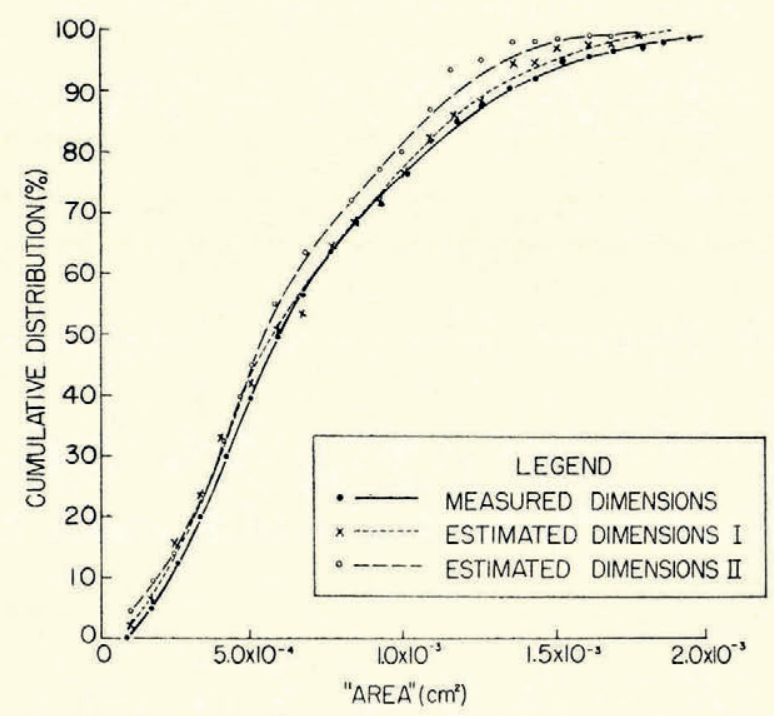

Fig. 4. Cumulative particle-size distribution curve for 200 snow particles, fraction $150-300 \mu$, using estimated and measured dimensions

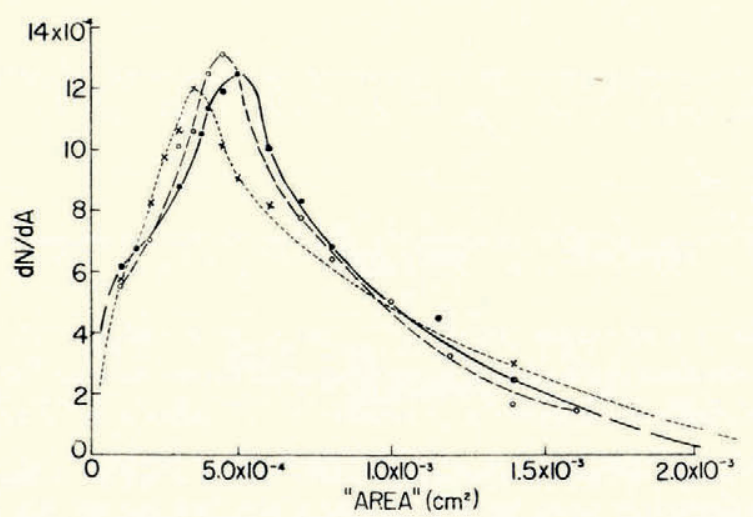

Fig. 5. Derivative particle-size distribution curve for 200 snow particles, fraction $150-300 \mu$, using estimated and measured dimensions

Table I. Particle-size Distribution of Pulverized Snow, Fraction i 50-300 $\mu$

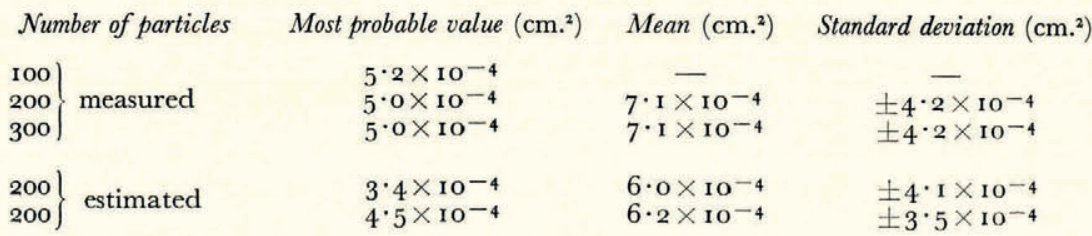

Fraction $0-150 \mu$

Figs. 6 and 7 show the cumulative curves for I00, 200, 300 and 400 measured particles of fraction $0-150 \mu$. The type of curve is similar to that for the $150-300 \mu$ fraction. It is clear that at least 300 particles have to be measured in order to obtain a representative distribution, although the most probable value can be ascertained by measuring a relatively 


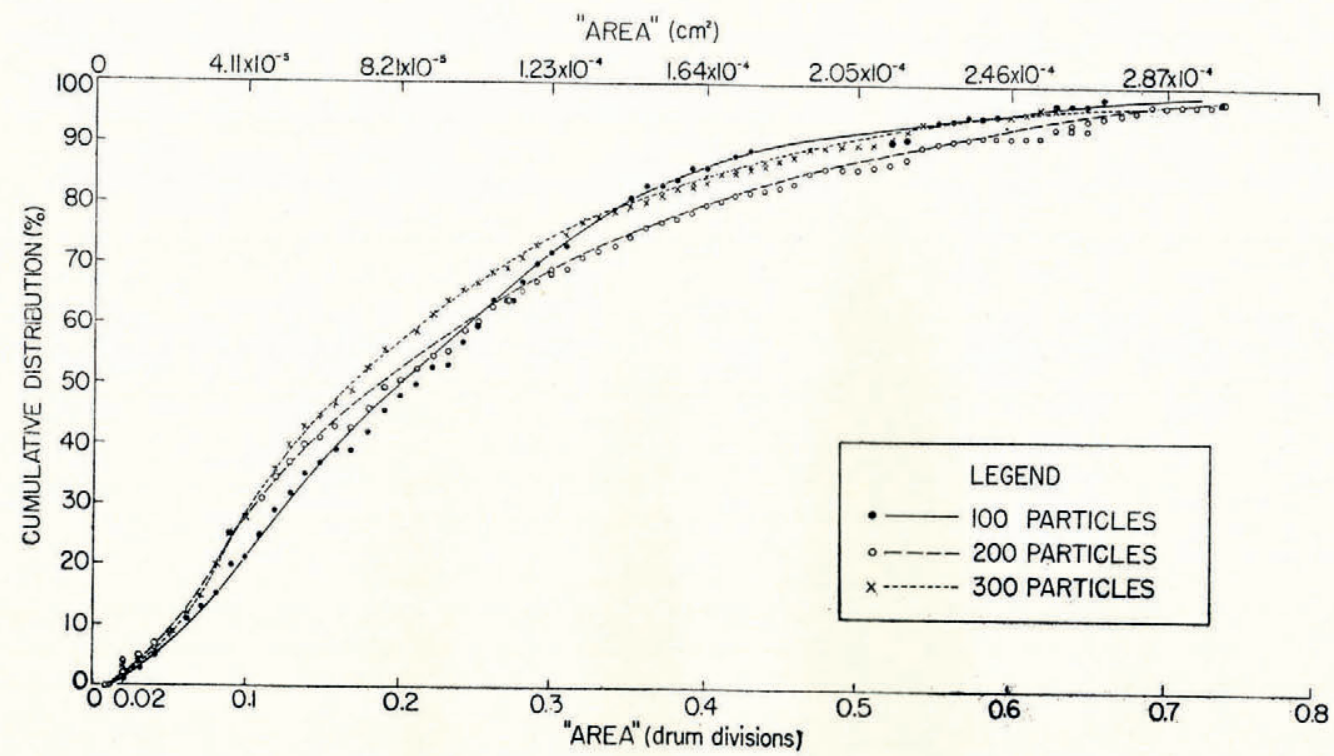

Fig. 6. Cumulative particle-size distribution curve for 100,200 , and 300 snow particles, fraction $0-150 \mu$

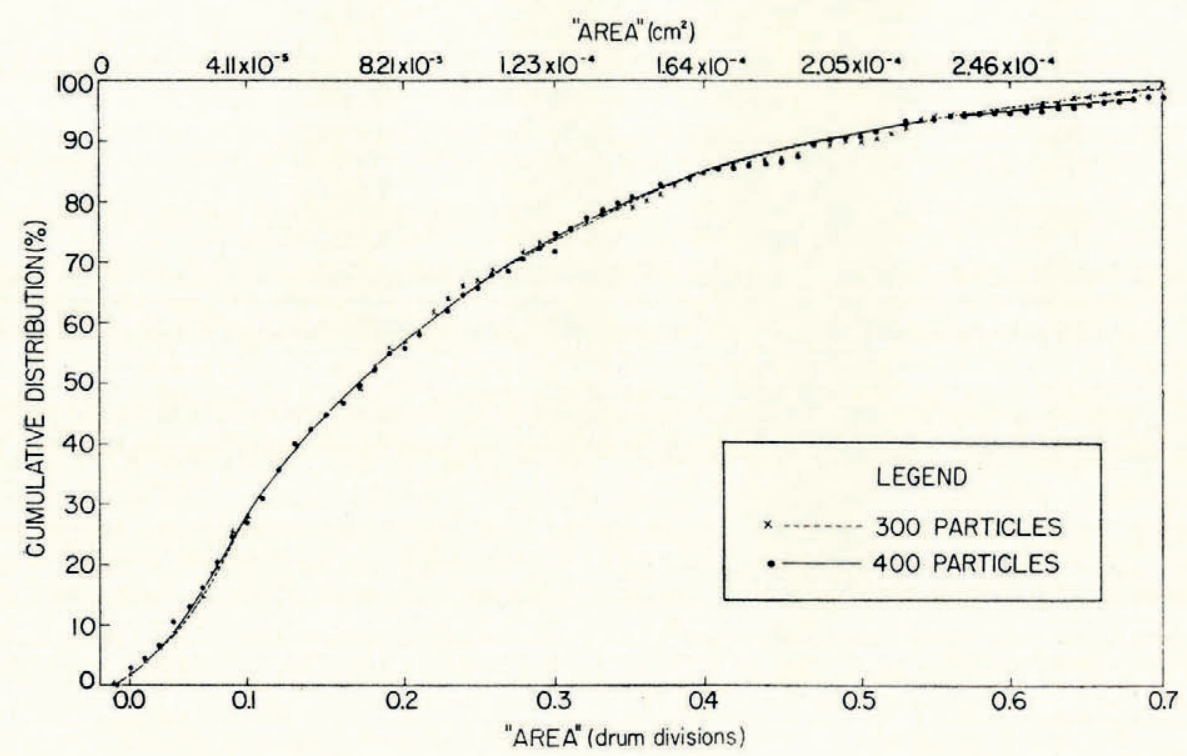

Fig. 7. Cumulative particle-size distribution curve for 300 and 400 snow particles, fraction $0-150 \mu$ 
small number of particles. Figs. 8 and 9 give the derivative curves for 300 and 400 measured particles.

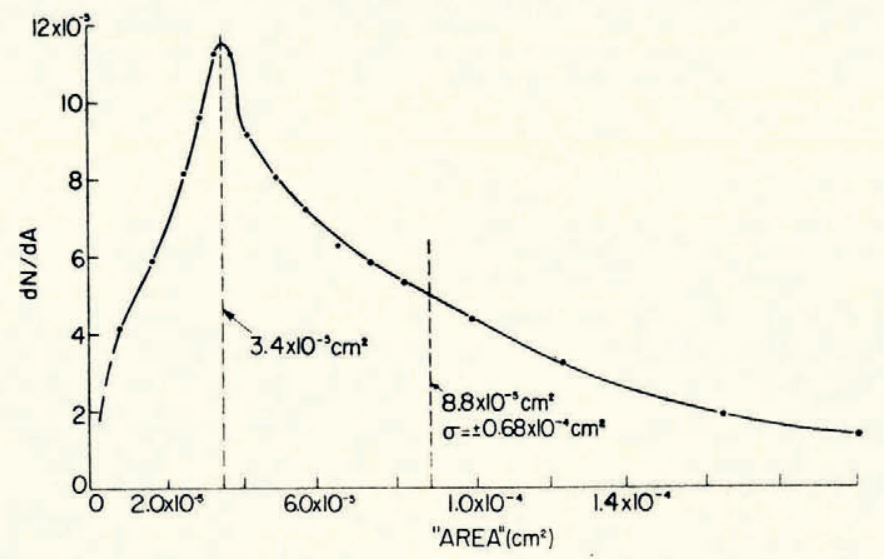

Fig. 8. Derivative particle-size distribution curve for 300 snow particles, fraction $0-150 \mu$

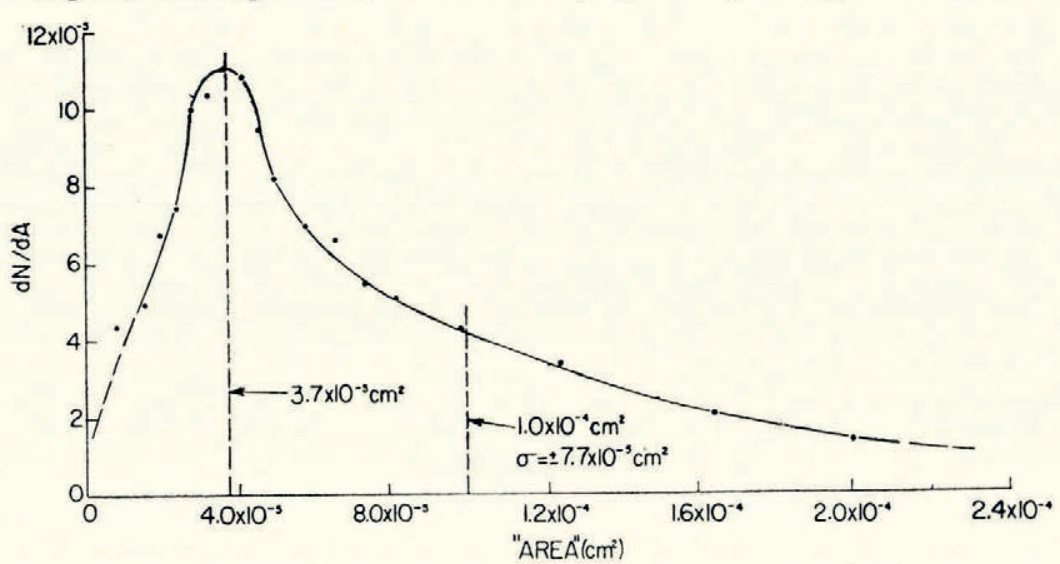

Fig. 9. Derivative particle-size distribution curve for 400 snow particles, fraction $\mathrm{O}-150 \mu$

Distributions obtained by estimating the sizes of 300 particles are shown in Figs. Io and II. Here again, acceptable results can be obtained by estimating the particle sizes if not too great an accuracy is needed. In this case the estimated values were larger than the measured values, again due to a personal factor. The miscoscope magnification in this case was different from that used for the I 50 to $300 \mu$ fraction. Characteristic values for the fraction 0 to ${ }^{2} 5^{\circ} \mu$ are given in Table II.

Table II. Particle-size Distribution of Pulverized Snow, Fraction o-i $50 \mu$

$\begin{array}{cccc}\text { Number of particles } & \text { Most probable value }\left(\mathrm{cm}^{2}\right) & \text { Mean }\left(\mathrm{cm}^{2}\right) & \text { Standard deviation }\left(\mathrm{cm} .^{2}\right) \\ 300 & 8 \cdot 8 \times 10^{-5} & \pm 6.8 \times 10^{-5} \\ 400 & 3.4 \times 10^{-5} & 1 \cdot 0 \times 10^{-4} & \pm 7 \cdot 7 \times 10^{-5} \\ 300 \text { estimated } & 3.7 \times 10^{-5} & 1 \cdot 0 \times 10^{-4} & \pm 7 \cdot 1 \times 10^{-5} \\ & 4.4 \times 10^{-5} & 1 \cdot 0 \times 10^{-4} & \end{array}$

Mixture of fractions

The final experiment was carried out on a I : I mixture by weight of the o to $150 \mu$ and I 50 to $300 \mu$ fractions.

Fig. I 2 shows the cumulative curve and Fig. 13 the derivative curve; 300 particles were measured in this case. 


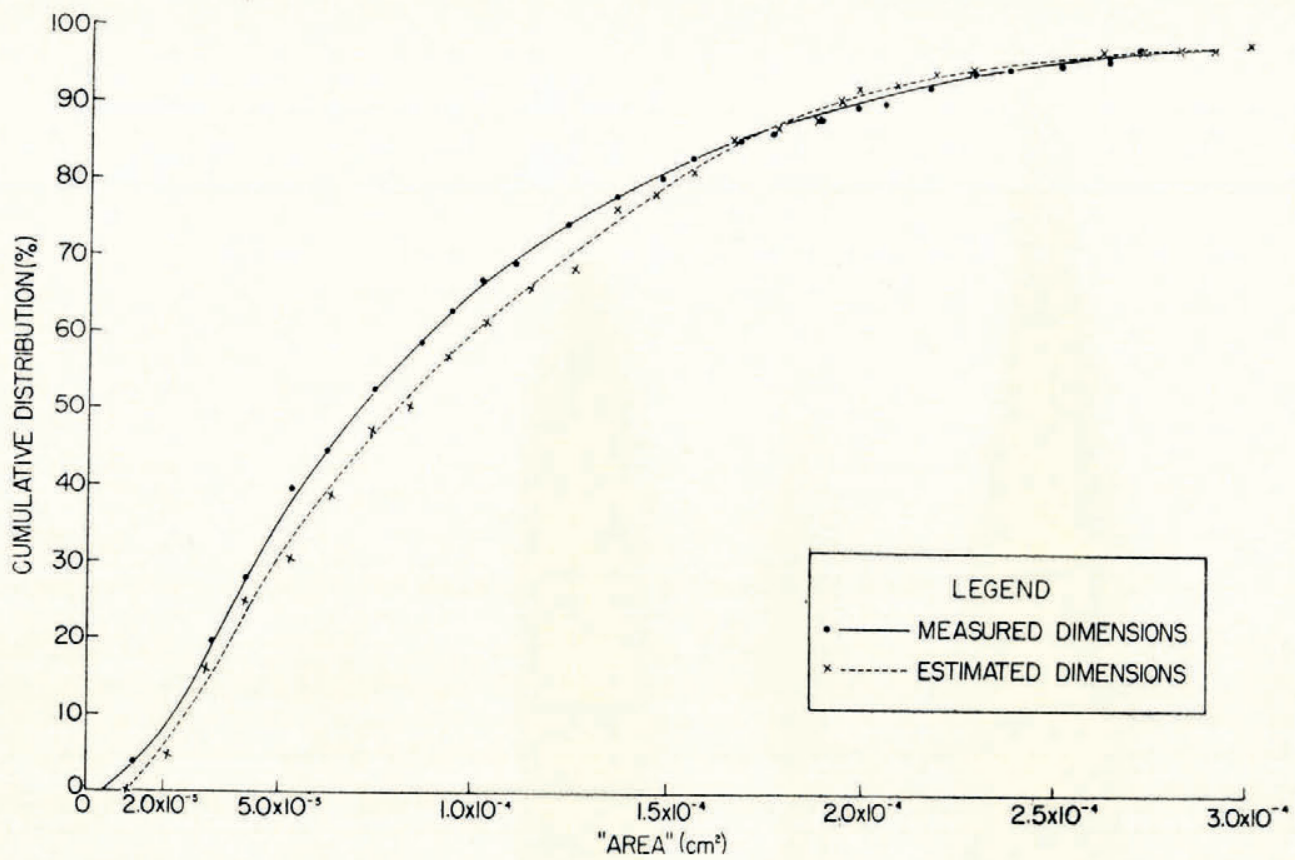

Fig. Io. Cumulative particle-size distribution curve for 300 snow particles, fraction $0-150 \mu$, using estimated and measured dimensions

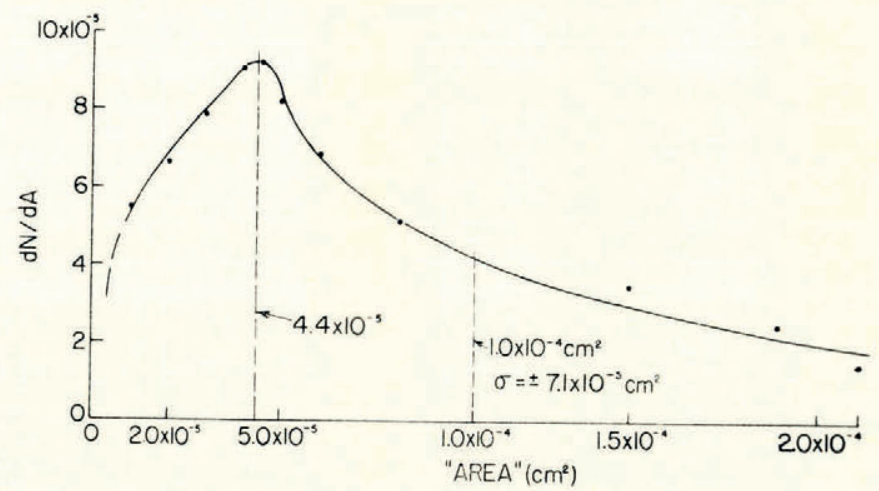

Fig. II. Derivative particle-size distribution curve for 300 snow particles, fraction $0-150 \mu$, using estimated dimensions

Derivative curves were also constructed from the results previously obtained for each fraction separately. The calculated curves for a I : I and I : 5 ratio, by number of particles of the larger size fraction to the smaller one, are shown in Figs. I4 and I5. Table III shows the characteristic constants for the mixture.

Table III. Particle-size Distribution of Pulverized Snow, Mixture of Fraction o to i50 $\mu$ and
Fraction 150 to $300 \mu$

\section{Number of particles}

300 measured calculated calculated

$\begin{array}{lc}\text { Ratio } & \\ \text { Large : Small } & \text { Most probable values }\left(\mathrm{cm}^{2}\right) \\ \text { I }: \text { I by weight } & 3.5 \times \mathrm{IO}^{-5} 4.5 \times \mathrm{IO}^{-4} \\ \text { I }: \text { I by number } & 3.5 \times \mathrm{IO}^{-5} 5.0 \times 1 \mathrm{O}^{-4} \\ \text { I }: 5 \text { by number } & 3.7 \times \mathrm{IO}^{-5} ; 4.5 \text { to } 5.0 \times \mathrm{IO}^{-4}\end{array}$

Mean
$\left(\mathrm{cm} .^{2}\right)$

$2 \cdot 1 \times 10^{-4}$

$4.0 \times 10^{-4}$

$0.90 \times 10^{-4}$
Standard deviation $\left(\mathrm{cm}^{2}{ }^{2}\right.$

$\pm 2.7 \times 10^{-3}$ 


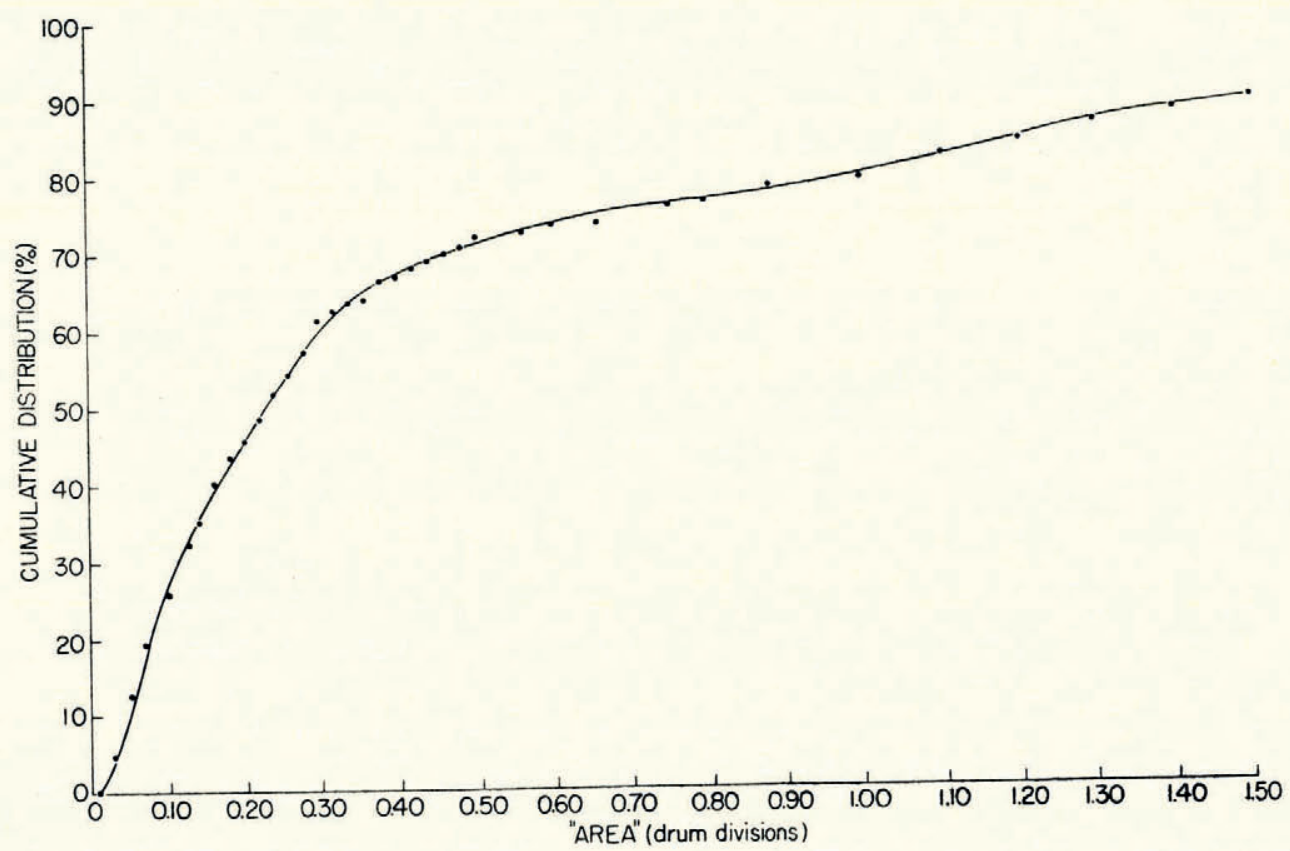

Fig. 12. Cumulative particle-size distribution curve for 300 particles, $I: I$ mixture by weight of $0-150 \mu$ and $150-300 \mu$ fractions

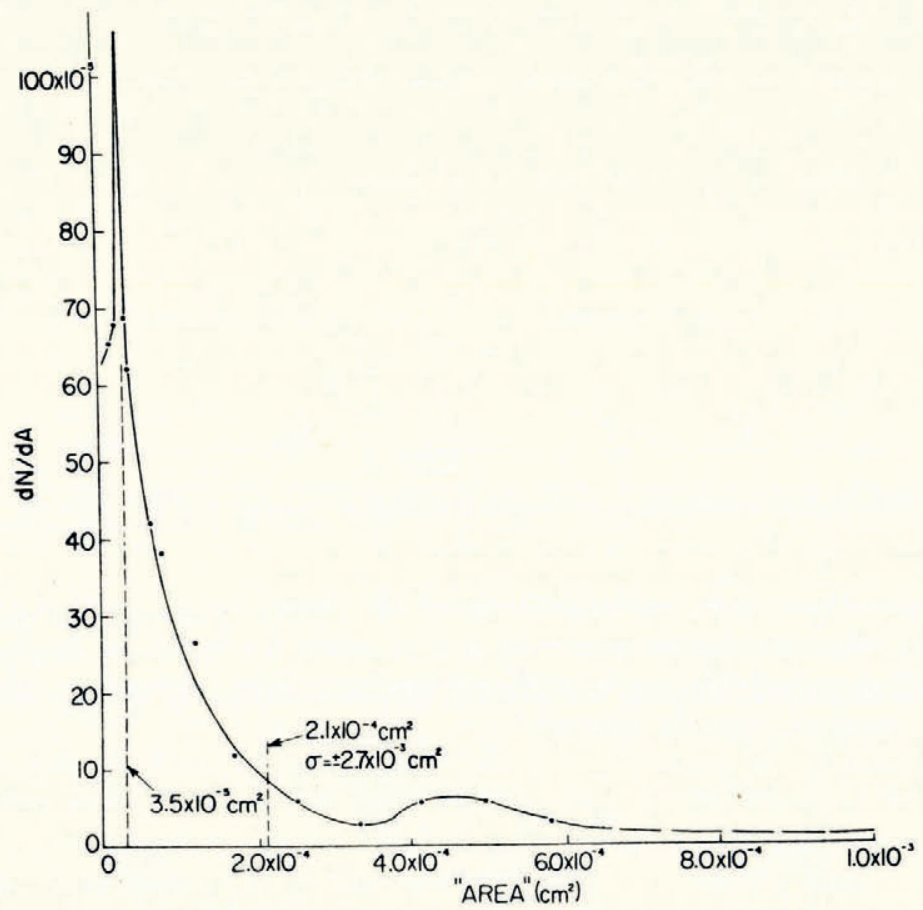

Fig. 13. Derivative particle-size distribution curve for 300 snow particles, I: I mixture by weight of $0-150 \mu$ and $150-300 \mu$ fractions 


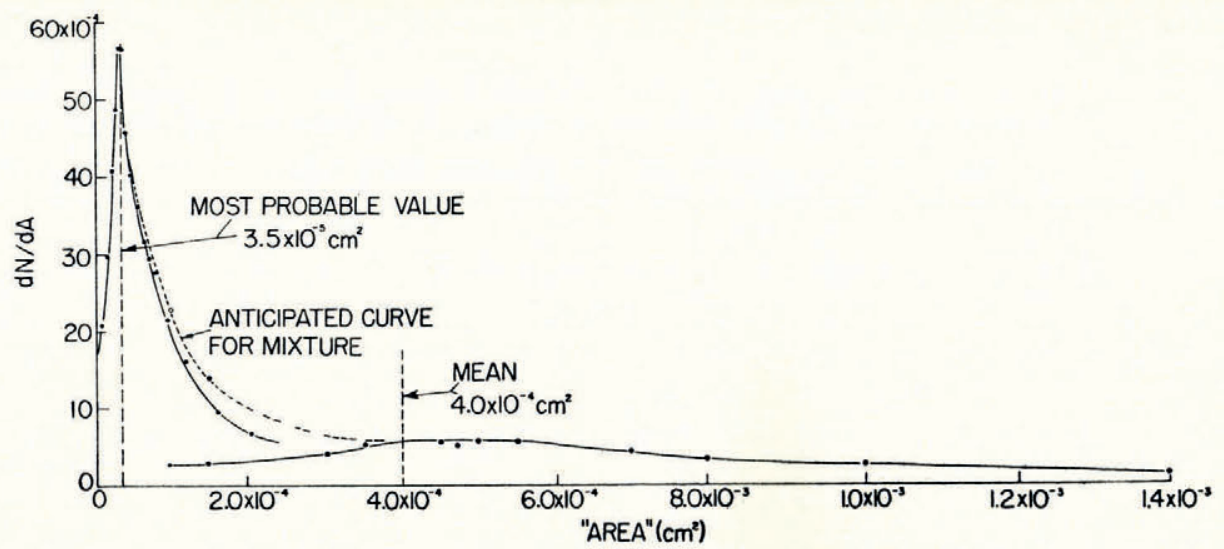

Fig. I4. Derivative particle-size distribution curve calculated for $I: I$ mixture by number of particles of fractions $1_{50-300 \mu}$ and $0-150 \mu$

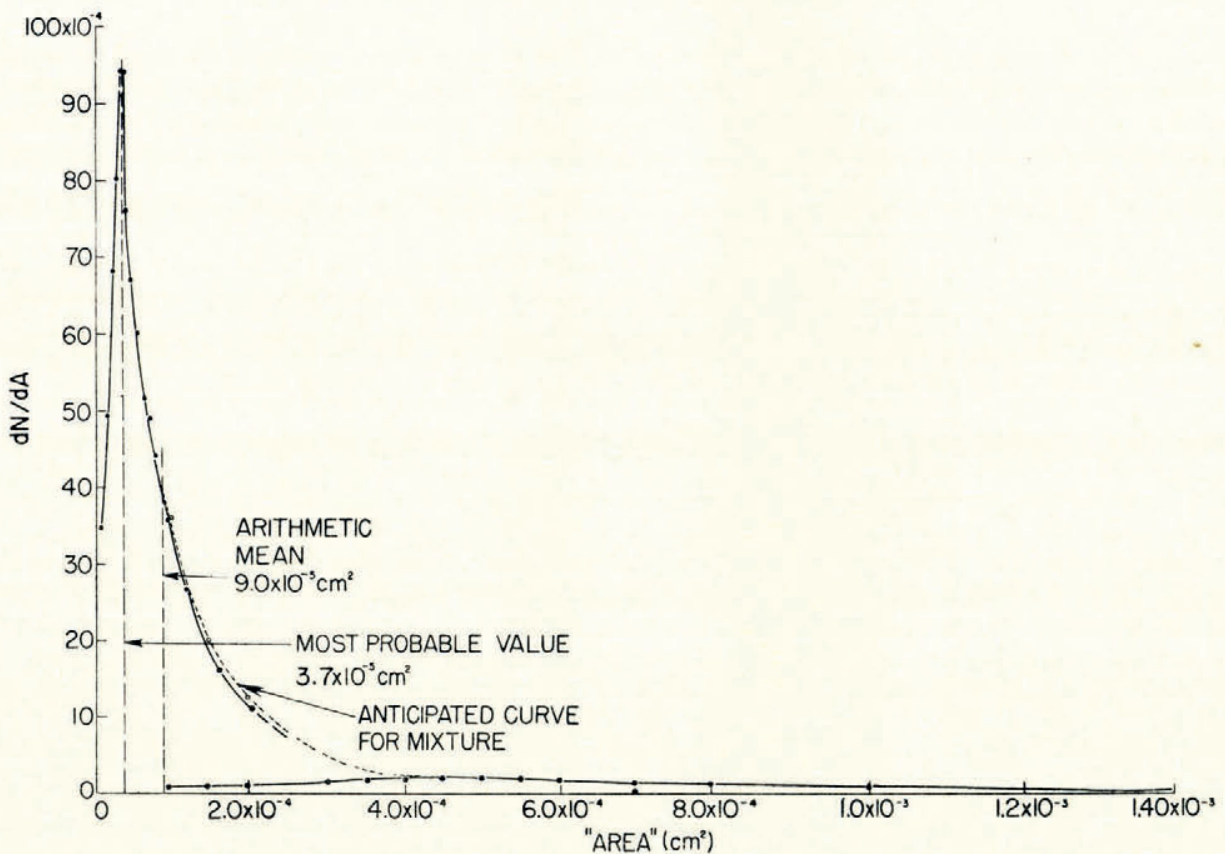

Fig. 15. Derivative particle-size distribution curve calculated for $1: 5$ mixture by number of particles of fractions $150-300 \mu$ and $0-150 \mu$

\section{Conclusions}

The microscopic method for the determination of number-size distributions of pulverized snow particles gives satisfactory distribution curves. At least 200 particles have to be measured to obtain a representative distribution. The time for the determination of a distribution can be appreciably shortened by estimating the size of the particles instead of measuring them, though the accuracy is not so high in this case.

If the microscopic method is used as a frequent routine analysis, it might be worthwhile to photograph the particles. The distribution could then be ascertained by scanning the photographs photoelectrically.

MS. received 29 July $195^{8}$ 